\title{
Comparison Among the Daily Levothyroxine Doses According to the Etiology of Hypothyroidism
}

\author{
Josivan Gomes de Limaa, b, c, Deciara Jacome Torres Medeiros de Mesquita \\ Flavia da Costa Fernandes ${ }^{a}$, Alexandre Barbosa Camara de Souza ${ }^{a}$, \\ Antonio Correia dos Santos Junior ${ }^{\mathrm{a}}$, Bartira Reboucas ${ }^{\mathrm{a}, \mathrm{b}}$, Natalia Nobrega de Lima ${ }^{\mathrm{a}}$, \\ Andre Gustavo P. Sousa ${ }^{a, b}$, Lucia Helena Coelho Nobrega ${ }^{a, b}$
}

\begin{abstract}
Background: The initial doses of levothyroxine (LT4) replacement therapy in patients with hypothyroidism in clinical practice are usually empirical, perhaps because of the lack of data suggesting how much hormone is needed in each patient's situation. The aim of our study is to evaluate the daily dose of oral LT4 needed to achieve the TSH goals in patients with hypothyroidism caused by different etiologies.
\end{abstract}

Methods: Patients were divided and analyzed according to the etiology of the hypothyroidism. We retrospectively evaluated data from 557 patients (501 women) with hypothyroidism who had normal serum TSH and free T4 (FT4) levels in at least two consecutive appointments in which they were using the same levothyroxine doses.

Results: The mean dose of levothyroxine in the total sample was $91.3 \pm 37.18 \mu \mathrm{g} /$ day $(1.39 \pm 0.63 \mu \mathrm{g} / \mathrm{kg} /$ day $)$. Stratifying by group: central hypothyroidism $53.94 \pm 28.07 \mu \mathrm{g} /$ day $(0.82 \pm 0.48 \mu \mathrm{g} / \mathrm{kg} /$ day); primary hypothyroidism (no intervention) $81.37 \pm 29.84 \mu \mathrm{g} /$ day $\left(1.25 \pm 0.53 \mu \mathrm{g} / \mathrm{kg} /\right.$ day); post radioactive iodine $\left(\mathrm{I}^{131}\right) 97.42$ $\pm 28.32 \mu \mathrm{g} /$ day $(1.33 \pm 0.55 \mu \mathrm{g} / \mathrm{kg} /$ day $)$; post-thyroidectomy for benign causes $102.8 \pm 36.96 \mu \mathrm{g} /$ day $(1.54 \pm 0.59 \mu \mathrm{g} / \mathrm{kg} /$ day $)$; postthyroidectomy for thyroid cancer $138.5 \pm 35.25 \mu \mathrm{g} /$ day $(2.17 \pm 0.58$ $\mu \mathrm{g} / \mathrm{kg}$-day).

Conclusions: The dose of LT4 required to stabilize the patient varies according to different hypothyroidism etiologies.

Keywords: Levothyroxine; Primary hypothyroidism; Thyroidectomy; Radioactive iodine; Central hypothyroidism

\footnotetext{
Manuscript accepted for publication April 15, 2013

${ }^{a}$ Departamento de Medicina Clinica, HUOL - Hospital Universitario Onofre Lopes, UFRN, Natal, RN, Brazil

${ }^{\mathrm{b}} \mathrm{CEN}$ - Centro de Endocrinologia de Natal, Natal, RN, Brazil

${ }^{\mathrm{C} C o r r e s p o n d i n g ~ a u t h o r: ~ J o s i v a n ~ G o m e s ~ d e ~ L i m a, ~ D e p a r t a m e n t o ~ d e ~}$

Medicina Clinica, HUOL - Hospital Universitario Onofre Lopes,

UFRN, Natal, RN, Brazil. Email: josivanlima@gmail.com
}

doi: http://dx.doi.org/10.4021/jem165w

\section{Introduction}

Hypothyroidism is a condition defined by partial or total deficit of thyroid hormone. It is a common condition and is more prevalent in women, especially the most elderly [1]. The National Health and Nutrition Examination Survey III (NHANES III) data estimates the prevalence of hypothyroidism in the American population at $0.3 \%$ [2]. Studies in the United States, Europe, and Japan have reported the prevalence of hypothyroidism to be between 0.6 and 12 per 1,000 in women and between 1.3 and 4.0 per 1,000 in men [3].

A variety of functional or structural disorders can cause hypothyroidism. Primary hypothyroidism is the inability of the thyroid gland to supply a sufficient amount of the thyroid hormone and can be caused by inherited biosynthetic defects, deficient iodine supply, inhibition of hormonogenesis by various drugs and chemicals, or, most commonly, autoimmune dysfunction. Central hypothyroidism is due to inadequate stimulation of an intrinsically normal thyroid gland resulting from a defect at the level of the pituitary (secondary hypothyroidism) or the hypothalamus (tertiary hypothyroidism). Hypothyroidism can also be caused by ablation with radioactive iodine $\left(\mathrm{I}^{131}\right)$ or by thyroidectomy for benign or malign conditions.

Hypothyroidism is preferably treated with thyroid hormone replacement in the form of levothyroxine, due to its prolonged half-life, absorption $(80 \%$ intestinal, predominantly jejunal), and good oral availability. It should be administered in a single daily dose, before the first meal, given the fact that it is better absorbed in the fasting state [4].

In clinical practice, the goal of treatment is to keep normal serum levels of Thyroid Stimulating Hormone (TSH), except in post-surgery thyroid cancer patients, in which the goal is to keep TSH at suppressed levels; and in central hypothyroidism patients, in which the goal is to keep serum levels of Free Thyroxin (FT4) in the upper half of the normal range [5]. However, the necessary levothyroxine dose to be complemented in order to normalize hormone levels depends on several factors, including: etiology of the hypothyroidism, age, weight, gender, duration and severity of hypothyroidism, and associated comorbidities (heart disease, 
for example) [5].

For the complete hormone replacement in young adults with no active thyroid tissue, some authors defend that the expected daily dose required to fulfill the goals above vary from 100 to $150 \mu \mathrm{g}$ for women or 125 to $200 \mu \mathrm{g}$ for men. If calculated by $\mathrm{kg}$, the dose varies from 1.6 to $1.8 \mu \mathrm{g} / \mathrm{kg} /$ day. However, this has not been well characterized yet [5]. Nevertheless, for newly diagnosed patients with hypothyroidism, it is difficult to predict the final dose each patient will require, so that often the dose is started empirically and adjustments are performed according to TSH and/or FT4 results. Furthermore, beyond the factors previously described, it is possible that regional or ethnic factors may play a role in the variation of required levothyroxine dose. Therefore, studies in different populations may help clarify these factors to help clinicians in choosing the closest initial dose of levothyroxine required for patients with hypothyroidism, thereby reducing the costs of hormonal dosages.

The aim of this study was to evaluate the required daily dose of levothyroxine to achieve the goal of TSH according to the etiology of hypothyroidism, gender, weight and age.

\section{Materials and Methods}

Data of 1324 patients with hypothyroidism were evaluated retrospectively from June 2006 to January 2012. Inclusion criteria were euthyroidism (TSH between 0.4 and $4.0 \mathrm{ng} / \mathrm{dL}$, FT4 between 0.5 and $2.2 \mathrm{ng} / \mathrm{dL}$ ) in two consecutive visits, on the same levothyroxine dose for both visits. An exception was necessary regarding the patients who underwent thyroidectomy because of thyroid cancer, for which the normal range was established as TSH $\leq 0.4 \mathrm{ng} / \mathrm{dL}$ and FT4 between 0.5 and $2.2 \mathrm{ng} / \mathrm{dL}$. The final eligible sample was 547 patients.

The patients were divided into the following groups according to the etiology of hypothyroidism: primary hypothyroidism $(\mathrm{n}=357)$, hypothyroidism post-ablation with radioactive iodine $(\mathrm{n}=20)$, post-thyroidectomy hypothyroidism for benign causes $(n=92)$, post-thyroidectomy hypothyroidism for malignant causes $(n=62)$, and central (pituitary or hypothalamic) hypothyroidism $(\mathrm{n}=16)$.

The entire sample was stratified by age into the following groups: 20 years or younger, 21 to 30 years, 31 to 40 years, 41 to 50 years, 51 to 60 years, 61 to 70 years, and older than 70 years. As there were no data regarding menopausal status in women, the female sample was stratified into two groups in order to evaluate some possible influence of estrogen on the levothyroxine requirement: 50 years or younger and older than 50 years. The following variables were collected: age, gender, weight, body mass index (BMI), type of hypothyroidism, TSH, FT4, and levothyroxine dose at each visit. BMI was calculated dividing the weight by the squared height and the population was stratified into normal weight (BMI $<25 \mathrm{~kg} / \mathrm{m}^{2}$ ), overweight $\left(\mathrm{BMI} \geq 25 \mathrm{~kg} / \mathrm{m}^{2}\right.$ and $<30 \mathrm{~kg} /$ 
Table 2. Mean Dose of Levothyroxine $(\mu \mathrm{g})$ According to the Hypothyroidism Etiology

\begin{tabular}{|c|c|c|c|c|c|c|}
\hline & $\begin{array}{l}\mathbf{C H}^{1} \\
(\mathrm{n}=16)\end{array}$ & $\begin{array}{l}\mathbf{P H}^{\mathbf{2}} \\
(\mathrm{n}=357)\end{array}$ & $\begin{array}{l}\text { Post-I }{ }^{131} \\
(n=20)\end{array}$ & $\begin{array}{l}\text { Thyroidectomy } \\
\text { (benign) }(\mathrm{n}=92)\end{array}$ & $\begin{array}{l}\text { Thyroidectomy } \\
\text { (neoplasia) }(n=62)\end{array}$ & P value* \\
\hline Dose/day & 53.94 & 81.37 & 97.42 & 102.8 & 138.5 & $<0.0001$ \\
\hline SD & 28.07 & 29.84 & 28.32 & 36.96 & 35.25 & - \\
\hline Dose/weight/day & 0.81 & 1.24 & 1.33 & 1.54 & 2.16 & $<0.0001$ \\
\hline SD & 0.48 & 0.53 & 0.55 & 0.59 & 0.58 & - \\
\hline
\end{tabular}

${ }^{1} \mathrm{CH}$ : central hypothyroidism. ${ }^{2} \mathrm{PH}$ : primary hypothyroidism. Dose/day: $\mu \mathrm{g} / \mathrm{day}$. Dose/weight/day: $\mu \mathrm{g} / \mathrm{kg} / \mathrm{day}$. SD: standard deviation. $\left({ }^{*}\right)$ $P$ value for comparison among the groups. Bonferroni's post-hoc analysis: Hypothyroidism for malignant causes vs all other: $P<0.001$; $\mathrm{CH}$ vs $\mathrm{PH}: \mathrm{P}=0.008 ; \mathrm{CH}$ vs Post-I131: $\mathrm{P}=0.001 ; \mathrm{CH}$ vs post thyroidectomy: $\mathrm{P}<0.001 ; \mathrm{PH}$ vs Post I131: $\mathrm{P}=0.319 ; \mathrm{PH}$ vs thyroidectomy for benign causes: $P<0.001$; Post $I^{131}$ vs thyroidectomy for benign causes: $P=1.0$.

$\mathrm{m}^{2}$ ), and obese (defined as BMI $\geq 30 \mathrm{~kg} / \mathrm{m}^{2}$ ). Also collected in the post-surgery group was the cause of surgery (benign or malignant), and in the primary hypothyroidism group the diagnosis of Hashimoto was based on the presence of thyroid antibodies.

The analyses were performed using Graphpad Prism 4.0 and SPSS v.13 for Windows, with the data expressed as mean $\pm \mathrm{SD}$ if the distribution is parametric or median (range) if nonparametric. Chi-square tests, t-tests, and analysis of variance were used for comparisons according to characteristics of analyzed variables (parametric or non-parametric tests for continuous variables and the $\chi^{2}$ test and Fischer exact test for categorical variables). The ANOVA method was used for multiple comparisons for continuous variables and Bonferroni's post-hoc analysis was also used when appropriate. Linear regression was performed using coefficients of the linear equation, involving independent variables in order to predict the influence of the levothyroxine required dose (dependent variable), using an enter model. The probability (P value) less than 0.05 was considered statistically signifi- cant and 95\% confidence intervals (CI95) were calculated when appropriate.

\section{Results}

In the total eligible sample, $90.1 \%(n=494)$ were females. Patients were 7 to 93 years old with mean of $52.3 \pm 16.2$ years and there was no difference in age between the groups stratified by etiology (Table 1) (for baseline characteristics of population). The only difference was in gender, as in the group of central hypothyroidism there was not a great preponderance of females.

In the total sample, the mean TSH and FT4 levels in the second visit were $1.53 \pm 0.1 \mathrm{ng} / \mathrm{dL}$ and $1.39 \pm 0.34 \mathrm{ng} / \mathrm{dL}$, respectively. There was no difference among the groups, $(\mathrm{P}$ $=0.65$ and $\mathrm{P}=0.29$, respectively) with the exception of the post-thyroidectomy for the carcinoma group (mean TSH of $0.08 \pm 0.09 \mathrm{U} / \mathrm{mL}$ and FT4 $1.8 \pm 0.5 \mathrm{ng} / \mathrm{dL}$ ) and the central hypothyroidism group (mean TSH of $1.4 \pm 0.7 \mathrm{U} / \mathrm{mL}$ and

Table 3. Mean Dose of Levothyroxine ( $\mu \mathrm{g})$ According to Age (Years)

\begin{tabular}{lllllllll}
\hline Years & $\begin{array}{l}\leq \mathbf{2 0} \\
(\mathrm{n}=23)\end{array}$ & $\begin{array}{l}\mathbf{2 1}-\mathbf{3 0} \\
(\mathrm{n}=36)\end{array}$ & $\begin{array}{l}\mathbf{3 1} \mathbf{- 4 0} \\
(\mathrm{n}=53)\end{array}$ & $\begin{array}{l}\mathbf{4 1}-\mathbf{5 0} \\
(\mathrm{n}=119)\end{array}$ & $\begin{array}{l}\mathbf{5 1 - 6 0} \\
(\mathrm{n}=148)\end{array}$ & $\begin{array}{l}\mathbf{6 1}-\mathbf{7 0} \\
(\mathrm{n}=101)\end{array}$ & $\begin{array}{l}>\mathbf{7 0} \\
(\mathrm{n}=62)\end{array}$ & P value \\
\hline Dose/day & 70.17 & 98.29 & 90 & 97.82 & 92.45 & 84.61 & 91.57 & 0.02 \\
$\mathrm{SD}$ & 31.70 & 47.42 & 37.87 & 35.82 & 36.40 & 32.99 & 1.06 & - \\
Dose/weight/day & 1.66 & 1.49 & 1.4 & 1.41 & 1.41 & 1.27 & 1.37 & 0.24 \\
$\mathrm{SD}$ & 1.005 & 0.76 & 0.66 & 0.60 & 0.58 & 0.51 & 0.32 & - \\
\hline
\end{tabular}

Dose/day: $\mu g / d a y$. Dose/weight/day: $\mu \mathrm{g} / \mathrm{kg} / \mathrm{day}$. SD: standard deviation. 
Table 4. Linear Regression for Final Required Levothyroxine Doses (Dependent Variable).

\begin{tabular}{lll}
\hline Variable & $\boldsymbol{\beta}$ Coefficient & P Value $\left(^{*}\right)$ \\
\hline BMI & -0.112 & 0.165 \\
Weight & 0.229 & 0.004 \\
Age & -0.024 & 0.550 \\
Gender & 0.111 & 0.006 \\
Etiology & 0.492 & $<0.001$ \\
\hline
\end{tabular}

$\left({ }^{*}\right)$ a variable was considered independently significant only when the $p$ value was below the threshold for Bonferroni's correction (in this case $\mathrm{P}$ value $<0.01$ ).

FT4 $1.1 \pm 0.7 \mathrm{ng} / \mathrm{dL})$.

In the primary hypothyroidism group, the Hashimoto diagnosis was confirmed in $14 \%$ of cases $(n=50)$ based on positivity of anti-thyroid autoantibodies. In $11.8 \%$ of patients $(\mathrm{n}=42)$, this diagnosis was not confirmed (negative antibodies). For the remaining $(74.2 \%, \mathrm{n}=265)$, no data were available.

The mean dose of levothyroxine for the total sample was $91.2 \pm 37.1 \mu \mathrm{g} /$ day and, adjusting by the weight, it was $1.39 \pm 0.63 \mu \mathrm{g} / \mathrm{kg} /$ day. The replacement dose of levothyroxine varied according to the etiology of hypothyroidism. The mean daily doses of levothyroxine, adjusted per body weight, were higher in the post thyroidectomy for the malignant cause group and lower in the central hypothyroidism group. Table 2 shows an overall comparison among the replacement doses in the groups stratified by etiology. According to gender, there were no differences between women and men, neither in the levothyroxine daily dose $(90.7 \pm 36.5$ vs. $97.3 \pm 42.5 \mu \mathrm{g} /$ day, $\mathrm{P}=0.22)$, nor in the per $\mathrm{kg}$ dose $(1.40 \pm$ 0.58 vs. $1.44 \pm 0.82 \mu \mathrm{g} / \mathrm{kg} / \mathrm{day}, \mathrm{P}=0.64$ ).

Table 3 shows an overall comparison between the replacement doses among the groups stratified by age. The group $<20$ years old had the lowest daily dose, but the highest dose per corporal weight. This can be justified by the fact that the youngest group presented the lowest mean weight $(46.8 \mathrm{~kg})$. The 20 - 30 year-old group had the highest daily dose, $98.29 \mu \mathrm{g} /$ day $(1.49 \mu \mathrm{g} / \mathrm{kg} /$ day $)$. The total daily dose decreased after age $50(\mathrm{P}=0.02)$, but there was no statistical difference between the dose per body weight in any of the groups $(\mathrm{P}=0.24)$.

In order to evaluate whether the body weight (BMI) also influences the required dose, the total sample was stratified by BMI. Interestingly, there were no differences in the levothyroxine replacement dose among the groups of normal BMI, overweight, and obese $(P=0.465)$. However, analyzing multiple variables in a linear regression, using the re- quired levothyroxine dose as the dependent variable, the weight (but not the BMI), gender, and etiology of hypothyroidism were independently associated with the final dose of LT4 (Table 4) in the total sample, even considering a more strict $p$ value (by Bonferroni's correction). Similarly, for the primary hypothyroidism sample, both weight and gender were associated with the required levothyroxine dose (P values 0.014 and 0.011 , respectively).

Stratifying the female sample by age $(\leq 50$ years vs. $>50$ years), it was found that the mean dose/day ( $93.38 \pm 38$ vs. $88.60 \pm 35.4 \mu \mathrm{g} /$ day, $\mathrm{P}=0.14)$ and the mean dose/day adjusted by weight $(1.44 \pm 0.64 \mathrm{vs} .1 .35 \pm 0.58 \mu \mathrm{g} / \mathrm{kg} /$ day, $\mathrm{P}=$ 0.10 ) were slightly higher in the group $\leq 50$ years. However, these findings were not statistically significant.

\section{Discussion}

In this study we found that the levothyroxine replacement dose increases in the following order: central hypothyroidism, primary hypothyroidism, post ablation with $\mathrm{I}^{131}$ hypothyroidism, post-surgery hypothyroidism (non-cancer), and post-surgery hypothyroidism (cancer). An explanation for such findings could be that patients with less residual functioning thyroid tissue may require higher doses than those with more residual tissue. These results are important in that they can help physicians and endocrinologists in choosing the initial dose of levothyroxine replacement in patients with hypothyroidism.

The etiology of hypothyroidism influences the levothyroxine replacement dose, since it is inversely correlated with the functionality of thyroid tissue. Patients who have had a total thyroidectomy or radioactive-iodine ablation of the thyroid may require higher doses than those with residual functioning thyroid tissue [5].

The levothyroxine dose needed for suppression of TSH 
in patients with thyroid carcinoma has usually been reported to be $2.2 \mu \mathrm{g} / \mathrm{kg} / \mathrm{day}$, but replacement doses needed for euthyroidism in athyreotic patients with thyroid carcinoma have not been well characterized in a sizable population [6]. Other authors described a mean levothyroxine dosage for post-thyroidectomy hypothyroidism for malignant causes between 2.04 and $2.11 \mu \mathrm{g} / \mathrm{kg} / \mathrm{day}$ [5-7]. This dosage is similar to that found in our study. In the post-thyroidectomy hypothyroidism (non-cancer) group, the dose was lower. Patients who underwent thyroidectomy for benign causes can have some residual thyroid mass producing thyroid hormones, requiring a lower dose of levothyroxine. Besides that, the goal of hormone levels in the malignant group is the suppression of TSH (TSH < 0.4), differently from the other groups, and for that, a higher dose of levothyroxine is needed.

Gordon et al found that the dose needed for patients who underwent ablation with iodine is $1.56 \mu \mathrm{g} / \mathrm{kg} / \mathrm{day}$ [5], slightly higher than that found in our study $(1.33 \pm 0.55 \mu \mathrm{g} / \mathrm{kg} / \mathrm{day})$. It is expected that these patients require less hormone than the post-surgery group and more hormone than the primary hypothyroidism group, as the $\mathrm{I}^{131}$ ablation can leave more residual functioning thyroid tissue than surgery, but less tissue than the causes of primary hypothyroidism. Interestingly, in this study [5] the doses required to normalize TSH in benign cases (excluding cancer) were lower than in other studies in different populations. This contrast could mean either a difference in clinical therapeutic targets proposed by our physicians or ethnic differences or even molecular variations (deiodinases expression, for example). Obviously, methodological differences could also explain these results.

Gordon et al also showed [5] that the replacement dose of levothyroxine for patients with central hypothyroidism $(\mathrm{CH})$ was significantly higher than that for the other groups $(150 \mu \mathrm{g} /$ day $)$; however, this was the dose needed to keep serum levels of LT4 on the upper half of the normal range. Ferretti et al [8] found the mean daily dose of $1.5 \pm 0.3 \mu \mathrm{g} /$ $\mathrm{kg}$ for these patients, again a higher dose than that found in our study. Another study found no difference between replacement doses in patients with central or primary hypothyroidism [9]. In our analysis we found that these two groups required the lowest doses among all causes of hypothyroidism, and there was a statistical difference between the daily levothyroxine doses for body weight in these two groups $(\mathrm{P}=0.01)$ with the $\mathrm{CH}$ group needing the smaller dose. In general, no consensus has yet been achieved concerning the evaluation of the adequacy of the FT4 replacement dose [8].

We found that there was no statistical difference among TSH and FT4 levels in the different age groups. Previous studies revealed that age was found to affect the dose of levothyroxine needed for normalization of serum TSH. The dose per $\mathrm{kg}$ of body weight was found to be inversely related to age [10]. Rosenbaum et al [11] found that elderly patients with hypothyroidism need less daily levothyroxine than younger patients. On the other hand, Franklyn et al sug- gested that increasing age alone does not significantly influence thyroid hormone measurements [12]. A more recent study also suggested that age does not directly affect FT4 replacement requirements, and age-based differences in doses are secondary to differences in body weight and gender [13]. These findings correlate to the results of our categorical analyses.

In the female patients, there was also no statistical difference between the doses on the supposed pre- and post-menopausal groups. Although menopause does not bring marked changes in thyroid function, it nevertheless tends to reduce that function, especially when menopause occurs at the expected time [14]. Some studies have demonstrated influences of estrogens on the development, physiology, and pathology of the thyroid gland causing proliferation of thyroid tissue, which contains a large number of estrogen receptors [15]. However, it was shown that the effects of estrogen in the thyroid gland may be rather indirect, as a consequence of increased serum levels of thyroxin-binding globulin (TBG) in premenopausal women compared with those in menopause [12]. Other data suggest that these hormones may act directly on the pituitary through the release of TSH.

The data presented above explain the findings of previous studies (13) in which doses of levothyroxine needed for patients in menopause were smaller $(1.49 \mu \mathrm{g} / \mathrm{kg} /$ day $)$ than those of premenopausal patients $(1.51 \mu \mathrm{g} / \mathrm{kg} /$ day $)$. In our study, considering women under and over 50 years old, the dose was higher for the younger patients ( $<50$ years), but the difference was not statistically significant.

Our study had some limitations, but we do not believe these compromised the final results. This was a retrospective transversal study; therefore, we could only estimate but not determine whether there were causality relations between our variables. Although four different commercial preparations of levothyroxine were used for replacement, patients did not change from one to another during the study. The large number of patients and the fact that we considered two consecutive normal tests to ensure the stability of the dose of levothyroxine are strengths of our study, minimizing the potential limitations.

The findings of this study may help clinicians and endocrinologists who deal with hypothyroidism care. Our study reveals important characteristics of levothyroxine replacement, demonstrating differences in mean doses required for clinical management, according to the etiology of hypothyroidism. Furthermore, it was also observed that the etiology of hypothyroidism and weight of the patient may play a role in the total required levothyroxine daily dose. The initial level of TSH at diagnosis should also influence the dose needed for TSH normalization because it describes an estimate of the thyroid endogenous production.

In conclusion, the daily dose of levothyroxine required by patients with hypothyroidism varies according to the different etiologies, being lower in patients with central hypo- 
thyroidism and higher in patients with post-thyroidectomy due to thyroid carcinoma. There is no difference in the dose per $\mathrm{kg}$ /day according to age, but younger patients require smaller total doses per day. In addition, there is a linear association between the levothyroxine required dose and weight. This information can help the practitioner in choosing the initial replacement dose of levothyroxine.

\section{Disclosure Statement}

No competing financial interests exist.

\section{References}

1. Almandoz JP, Gharib H. Hypothyroidism: etiology, diagnosis, and management. Med Clin North Am. 2012;96(2):203-221

2. Hollowell JG, Staehling NW, Flanders WD, Hannon WH, Gunter EW, Spencer CA, Braverman LE. Serum TSH, T(4), and thyroid antibodies in the United States population (1988 to 1994): National Health and Nutrition Examination Survey (NHANES III). J Clin Endocrinol Metab. 2002;87(2):489-499.

3. Vanderpump MP. The epidemiology of thyroid disease. Br Med Bull. 2011;99:39-51.

4. Tandon N. Management of hypothyroidism in adults. J Assoc Physicians India. 2011;59 Suppl:21-25.

5. Gordon MB, Gordon MS. Variations in adequate levothyroxine replacement therapy in patients with different causes of hypothyroidism. Endocr Pract. 1999;5(5):233-238.

6. Burmeister LA, Goumaz MO, Mariash CN, Oppenheimer JH. Levothyroxine dose requirements for thyrotropin suppression in the treatment of differentiated thyroid cancer. J Clin Endocrinol Metab. 1992;75(2):344-350.
7. Sukumar R, Agarwal A, Gupta S, Mishra A, Agarwal G, Verma AK, Mishra SK. Prediction of LT4 replacement dose to achieve euthyroidism in subjects undergoing total thyroidectomy for benign thyroid disorders. World J Surg. 2010;34(3):527-531.

8. Ferretti E, Persani L, Jaffrain-Rea ML, Giambona S, Tamburrano G, Beck-Peccoz P. Evaluation of the adequacy of levothyroxine replacement therapy in patients with central hypothyroidism. J Clin Endocrinol Metab. 1999;84(3):924-929.

9. Banovac K, Carrington SA, Levis S, Fill MD, Bilsker MS. Determination of replacement and suppressive doses of thyroxine. J Int Med Res. 1990;18(3):210-218.

10. Mistry D, Atkin S, Atkinson H, Gunasekaran S, Sylvester D, Rigby AS, England RJ. Predicting thyroxine requirements following total thyroidectomy. Clin Endocrinol (Oxf). 2011;74(3):384-387.

11. Rosenbaum RL, Barzel US. Levothyroxine replacement dose for primary hypothyroidism decreases with age. Ann Intern Med. 1982;96(1):53-55.

12. Franklyn JA, Ramsden DB, Sheppard MC. The influence of age and sex on tests of thyroid function. Ann Clin Biochem. 1985;22 ( Pt 5):502-505.

13. Devdhar M, Drooger R, Pehlivanova M, Singh G, Jonklaas J. Levothyroxine replacement doses are affected by gender and weight, but not age. Thyroid. 2011;21(8):821827.

14. Bottiglioni F, de Aloysio D, Nicoletti G, Mauloni M, Mantuano R, Capelli M. A study of thyroid function in the pre- and post-menopause. Maturitas. 1983;5(2):105114 .

15. de Araujo LF, Soares JM, Jr., Simoes RS, Calio PL, Oliveira-Filho RM, Simoes Mde J, Haidar MA, et al. Effect of conjugated equine estrogens and tamoxifen administration on thyroid gland histomorphology of the rat. Clinics (Sao Paulo). 2006;61(4):321-326. 